\title{
Irradiated Fuel Monitoring by Cerenkov Glow Intensity Measurements
}

\section{MASTER}

PRC GRAM FOR 


\title{
IRRADIATED FUEL MONFTORING BY CERENKOV GLOW INTENSITY MEASUREMENTS
}

by

\author{
E. J. Dowdy, N. Nicholson, and J. T. Caldwell
}

\begin{abstract}
Attribute measurement techniques for confirmation of declared irradiated fuel inventories at nuclear installations under safeguards surveillance are being investigated. High-gain measurements of the intensity of the Cerenkov glow from exposed assemblies in water-filled storage ponds are promising for this purpose. Such measurements have been made of Materials Testing Reactior plate-type fuel assemblies and Pressurized Water Reactor pin-type fuel assemblies. The measured intensities depend on cooling times as calculations predict.
\end{abstract}

\section{INTRODUCTION}

Confirmation of declared irradiated fuel inventories in storage ponds of nuclear installations under safeguards surveillance and consistency checks of repeated inspections are responsibilities of both domestic and international safeguards inspectors. Currently, no fieldable hardware exists for carrying cut such inspections, but inventory verification techniques are being investigated vigorously. Under the US program for technical assistance to international safeguards, we are investigating several approaches to spent-fuel attribute measurements that were identified as promising in our earlier work. ${ }^{2}$ The criteria used for selecting promising techniques included ease of implementing the technique, simple interpretation of the measurement data, and minimal impact on the facility operator's routine schedule. Strict adherence to these criteria precludes any movement of the fuel assemblies. In addition, simple interpretation of the measurement data precludes sampling of nuclear radiation fields above the assemblies, as such data interpretation requires unfolding algorithms.*

The most promising technique satisfying our criteria is based on measuring the intensity of the Cerenkov glow resulting from the interaction of the radiation from fission products in the assemblies with the cooling water in the storage ponds. Currently, In iernational Atomic Energy Agency inspectors visually confirm the movement and storage of freshly exposed fuel assemblies during refueling operations when the Cerenkov glow from such intensely radioactive assemblies is visible. Although shortly thereafter the glow is not visible to the unaided eye, electronic light amplification renders the low light levels measurable. Beca.'se water has a very small attenuation coefficient tor visible and near-ultraviolet (uv) light, ${ }^{2}$ the measurements can

*Such was our experience in interpreting results of thermoluminescent dosimeter (TLD) measurnments of the Omega West Reactor fuel elements made at the same time as the Cerenkov measurements. TLD results will be included in a separate report. 
be made from above the storage-pond surface, obviating the introduction of equipment into the pond. For the standard vcrtical assembly storage, the penetrations in the upper mechanical structure of the assembly serve as Cerenkov light channels, allowing sampling of the nuclear radiaticn intensity to be much deeper than the top of the fuel assembly. The Cerenkov light intensity measurement is thus much less susceptible to crosstalk among adjacent assemblies than are nuclear radiation intensity measurements made at the tops of the assemblies.

The problem of crosstalk among assemblies has made in situ measurement results suspect in the past; it sometimes has been handled by moving an assembly from the normal storage rack to a location in the spent-fuel storage pool where the assembly is isolated from the remainder of the spent fuel. Fuel movement is usually possible in the storage ponds at reactor sites, but the Away From Reactor (AFR) storage facilities, like the General Electric Morris facility, ${ }^{3}$ probably will not accommodate such movement because the cover water is not deep enough to allow extraction of an assembly for passige over the remaining assemblies.

Cerenkov light intensities can be messured in several ways. We have concluded preliminary tests of the technique using imaging instruments that included a silicon-intensified target (SIT) video camera, an intensified silicon-intensified target (ISIT) video camera, a prototype hard-film camera that incorporates a microchannel plate image intensifier, and a standard hard-film camera with uv transmitting lenses. Images of both Materials Testing Reactor (MTR) plate-type fuel elements from the Los Alamos Scientific Laboratory (LASL) Omega West Reactor (OWR) and commercial Pressurized Water Reactor (PWR) pin-type assemblies from the Zion Nuclear Station have been made. The Cerenkov intensity was quantified by photometric measurements of selected bright spots on the recorded images corresponding to the waterfilled interstices of the assemblies. For this report, only measurements made with the SIT video camera are included. Results of earlier measurements using the ISIT camera, the microchannel plate image intensified film camera, and the standard camera with uv lenses are contained in a separate report."

\section{THEORETICAL BACKGROUND}

Electromagnetic Cerenkov radiation is emitted whenever a charged particle passes through a medium with a velocity exceeding the phase velocit $y$ of light in that medium. In water, the phase velocity of light is about $75 \%$ of the value in vacuum. Any electron passing through water and having $\geq 0.26-\mathrm{MeV}$ kinetic energy is thus a source of Cerenkov radiaticn. Irradiated fuel assemblies are a prolific source of beta and gamma rays and neutrons. All three types of emissions can produce Cerenkov light.

Considering the normal fuel rod cladding, we assume that few beta rays escape directly into the pond water and thus that beta rays are not a significant direct source of Cerenkov light. It is possible that electron bremsstrahlung from energetic beta rays interacting in the fuel rods could be a significant source of gamma radiation escaping into the pond water. In the water, energetic gamma rays undergo pair production or Compton scattering to produce $\geq 0.26-\mathrm{MeV}$ electrons. Neutrons may undergo $H(n, \gamma)$ reactions in the water and produce Cerenkov light through interactions of the $2.23-\mathrm{MeV}$ capture garnma rays with water.

The most significant production of Cerenkov light is from high-energy fission fragment-decay gamma rays that penetrate the cladding. The number of Cerenkov photons gen rated from gamma rays of any energy passing througn wä̀r can be calculated. Such calculations have been made and the resuits have been verified by experimental measurements with several radioactive gamma-ray sources. One calculation result is shown in Fig. 1. In this calculation, we assumed that the gamma rays must penetrate the equivalent of $5 \mathrm{~mm}$ of uranium before entering the water, thereby accounting for typical self-attenuation of the fuel and attenuation of the cladding.

Only Cerenkov photons in the visible range of 4000-6000 A were considered. The calculations indicate that Cerenkov light production is negligible for gamma rays with $\mathrm{E} \leq 0.6 \mathrm{MeV}$ and rises steeply with greater gamma-ray energy, reaching values of 50 or more Cerenkov photons per gamma ray for $E \geq$ $2 \mathrm{MeV}$. 


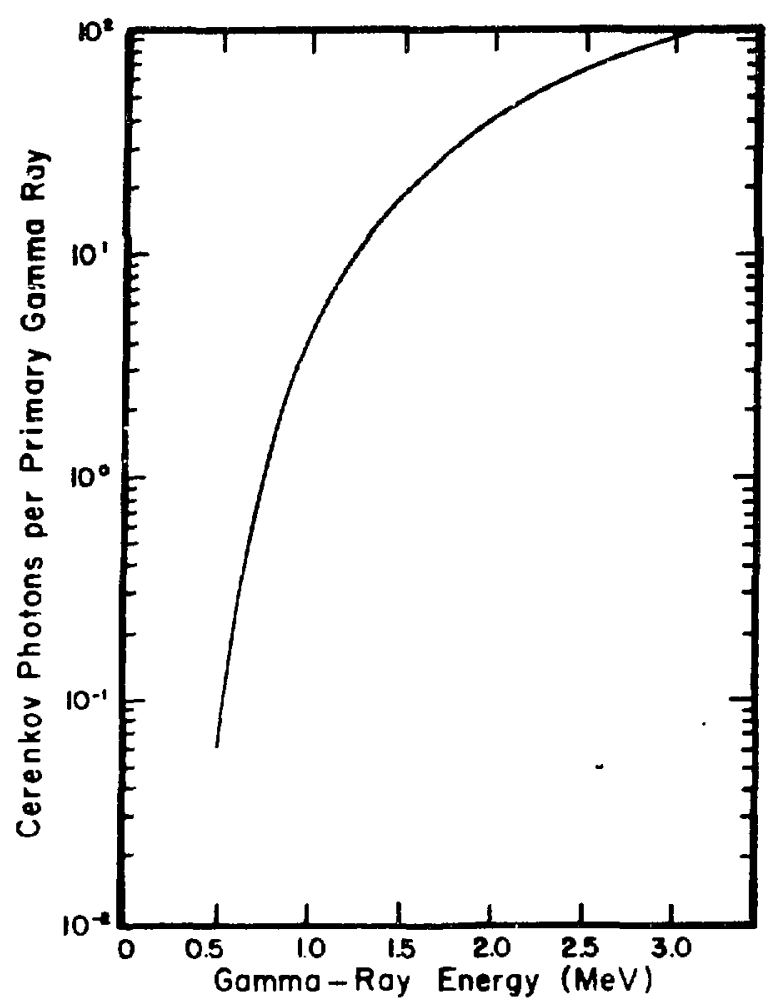

Fig. 1.

('erenkou photon production in water as a function of gamma-ray energy (4000-6000 A photon u'atrlengths). Camma rays are emitted hehind $5 \cdot \mathrm{mm}$ uranium equivalent shielding.

We have calculated Cerenkov light intensity as a function of exposure and coolinir time. We used ${ }^{285} \mathrm{U}$ thermal fission data and incluard all signioîcant fission fragment gamma activities giving rise to gamma rays with $\mathrm{E} \geq 0.6 \mathrm{MeV}$. Using $1 \mathrm{MWD}$ (megawatt-day) $=2.85 \times 10^{21}$ fission events and assuming that a total exposure time for 30000 MWD/M'IU (megawatt-days per metric ton of uranium) is $10^{3}$ days and that no beta emissions contribute to the Cerenkov pruduction, the results for the calculated Cerenkov light intensities are shown in Fig. 2. Immediately after withdrawal from the core there appears to be little difference between high-and low-exposure material. However, at long times after withdrawal there is a nearly linear dependence on burnup.

From 10000 to $30000 \mathrm{MWD} / \mathrm{MTU}$ exposure material, we expect neutron emission rates of $\sim 10^{7}$

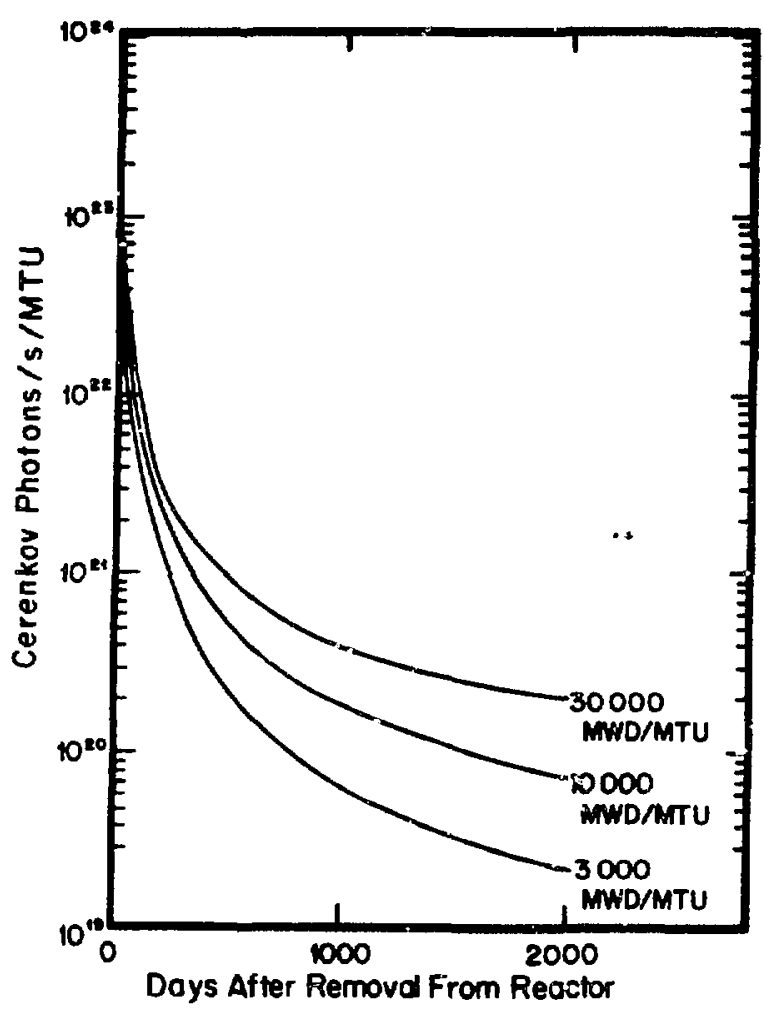

Fig. 2.

Cerenkov photon production in water between 4000 and $6000 \mathrm{~A}$ as a function of the exposure and cooling time of irradiated fuel.

to $10^{8} \mathrm{n} / \mathrm{s} / \mathrm{MTU}$. These rates generate Cerenkov light intensities of $\sim 10^{\theta}$ to $10^{11}$ photons/s/MTU by the ${ }^{1} \mathrm{H}(\mathrm{n}, \gamma)$ reaction, which is negligible compared $\mathrm{vith}$ the fission fragment gamma-ray induced source.

The information obtained from a Cerenkov measurement is burnup-related in that the absolute Cerenkov light level and its decay with time are related to burnup. Successful diversion either by substitution of dummy fuel assemblies or by incorrectly stating burnup would be difficult as long as the Cerenkov light intensity was measured ac. curately.

The spatial extent of the Cerenkov glow surrounding an isolated irradiated assembly in water probably will be deternined by the gamma radiation from the assembly's outer pins. The 10th-valuelayer thickness of water for $1.0-\mathrm{MeV}$ gamma rays is $\sim 36 \mathrm{~cm}$, which is a reasonable estimate of the 
Cerenkov "helo" around an isolated point source. Fission product radiation from an irradiated fuel assembly's inner pins, however, must penetrate a much denzer composice of fuel, cladding, and interstitial water, which greatly reduces crosstalk among assemblies in either regular or high-density storage racks.

\section{EXPERIMENTAL PROCEDURES}

Because deep sampling (for minimizing crosstalk arnong assemblies) of the fission product radiation is accomplished by detecting the Cerenkov radiation coming from deep within the assembly, the optical axis of the Cerenkov measuring instruments should be aligned with each assembly axis. The SIT video camera was aligned this way for the spent-fuel ineasurements at the LASL OWR. The SIT video camera was clamped to the spent-fuel storage pond bridge railing for the measurements of the Zion Station PWR assemblies; the bridge was used to transport the camera above the storage racks. Because each storage location has a larger crosssectional area than that of an assembly, assembly alignment was nonuniform. As shown in the results section, the lack of perfect alignment does not obviate the attribute measurements, but it leads to a presumed decrease in precision.

The experimental configurations of the five fuel elements used in the OWR measurements are shown in Fig. 3. The same calculational procedures used to generate the curves in Fig. 2 were used to estimate the inventory of fission products that give rise to Cerenkov photons. The fuel elements used in this test included three that were iserted in the reactor for a second exposure after having been removed following an initial burnup. This two-step burnup program adds some complexity to both the Cerenkov intensity calculations and the subsequent interpretations. The results of the calculations are given in Table $\mathbf{I}$.

At the Zion Station, two complete rows of the storage pond were imaged through about $8 \mathrm{~m}$ of water. These rows contained 28 fuel assemblies, i5 of which contained the standard PWR burnable poison pin cluster. The exposure and discharge dates of each are given in Table II. After assemblies in the storage racks were imaged, one recently clischarged assembly was extracted vertically and the
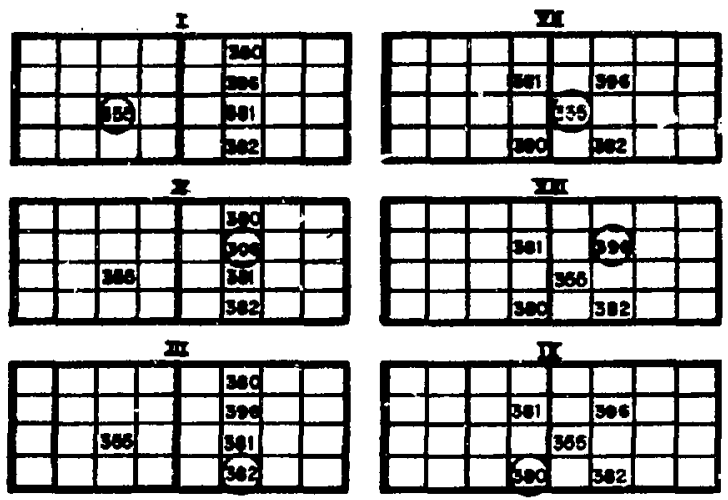

I.:
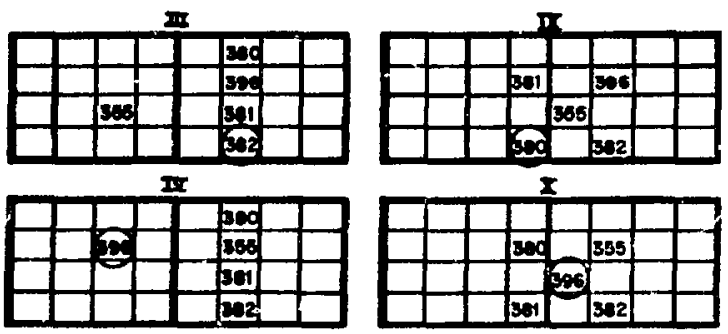

$r$
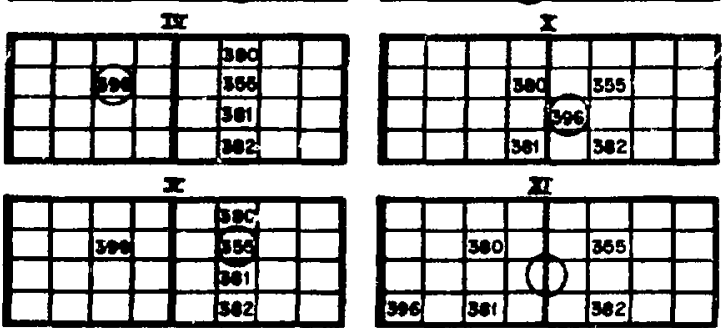

I

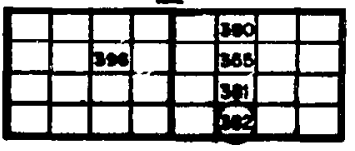

Fig. 3

Configurations of the MTR-type fuel elements used in the measurements at the OWR. Circle indicates the camera axis orientation.

entire assembly was imaged from the edge of the storage pond. This was done to confirm that radiation profiles also can be obtained using the Cerenkov intensity measurement technique. Radiation profiles have been used $^{6}$ with point measurements of fission product isotopic ratios to estimate assembly burnup.

Images of the fuel assemblies were recorded on video tape as a convenience for subsequent off-line analysis. On-line digital analysis of the analog video signais is possible with commercially available hardware. The video tapes were replayed, and individual frames were grabbed and stored on a video disk. Each selected single frame on the disk was displayed in conventional 512-line US television format on a cathode ray tube (CRT) with raster address using $x y$ cross hairs. The raster address size was a single pi isl. An associated electrometer indicated the electron current forming the intersection 
TABLE I

\section{EXPOSURE HISTORY AND CERENKOV INTENSITIES FOR OWR SPENT-FUEL ELEMENTS ON 9/18/78}

No. 1

\begin{tabular}{|c|c|c|c|}
\hline $\begin{array}{l}\text { Element } \\
\text { Number }\end{array}$ & In & Out & $\begin{array}{c}\text { Exposure } \\
\text { (MWD/MTU) }\end{array}$ \\
\hline $0-355$ & $?$ & $10 / 73$ & 38728 \\
\hline $0-380$ & $08 / 73$ & $07 / 76$ & 35200 \\
\hline $0-381$ & $08 / 73$ & $07 / 76$ & 35200 \\
\hline $0-382$ & $08 / 73$ & $08 / 76$ & 35400 \\
\hline $0-396$ & $01 / 75$ & $04 / 78$ & 39754 \\
\hline
\end{tabular}

No. 2

\begin{tabular}{ccccc}
\hline In & Out & $\begin{array}{c}\text { Exposure } \\
\text { (MWD/MTU) }\end{array}$ & $\begin{array}{c}\text { Cerenkov Intensity } \\
\text { (photons/s/MTU) }\end{array}$ \\
& & & $\ldots$ & $2.9 \times 10^{20}$ \\
$\cdots$ & $\ldots$ & $\ldots 800$ & & $2.5 \times 10^{21}$ \\
$11 / 77$ & $02 / 78$ & 4800 & & $2.5 \times 10^{22}$ \\
$11 / 77$ & $02 / 78$ & 4300 & & $2.3 \times 10^{21}$ \\
$11 / 77$ & $02 / 78$ & 4053 & & $5.4 \times 10^{21}$ \\
$\cdots$ &.-- & --- & &
\end{tabular}

pixel that is directly proportional to the pixel brightness. The brightness of pixels representing the Cerenkov glow in the interstitial water was determined in this way. To obtain a relative real-image brightness from the measured pixel brightness, the SIT camera lens aperture size variable was removed by normalizing all brightness to a common $\mathrm{f} / \mathrm{stop}$ value.

\section{RESULTS}

Figure 4 shows the video monitor display of a typical single video frame (1/30 s) of OWR fuel elements. Figs. 5 and 6 are the comparable displays for PWR assemblies, with the central assembly in Fig. 5 containing a poison pin cluster and that in Fig. 6 being an unpoisoned PWR assembly. The images resulting from the last two cases are obviously different, precluding confusion between the two.

The OWR and PWR data were handled in different but equivalent ways. For the OWR data, we compared each element's relative measured Cerenkov intensity with its calculated value for the fuel element configurations in which the element of interest was relatively isolated. These intensity values were all normalized to unity for the least radioactive element, No. 0-355. The results are given in Table III. A comparison of the calculated intensity values and the measured intensity values supports our claim that the Cerenkov intensity variation with exposure and cooling time-is calculable.
The last column in Table III contains three entries for element No. 0-355. The first entry is the normalized intensity for the isolated element. The second entry is the measured normalized intensity of the element No. 0-355 when two adjacent storage bins were occupied by elements with intensities approximately eight times greater than that of element No. $0-355$. The crosstalk amounts to about $10 \%$ in this case and corresponds to placing elements with comparable exposure, but with cooling times of 2 and 5 years, in adjacent storage locations. The third entry is the measured normalized intensity of element No. 0-355 when four diagonal storage locations were occupied by elements with average intensities more than 10 times greater than that of element No. 0-355. In this case, the crosstalk amounts to $90 \%$ of the measured intensity of the weakest element. However, this case corresponds to placing elements with comparable exposures, but with cooling times of 5 months and over 5 years, in such proximity.

The results of relative Cerenkov intensity measurements of the Zion PWR irradiated assemblies are shown in Fig. 7. The solid curve in the figure is the calculated intensity versus cooling time for an exposure of $30000 \mathrm{MWD} / \mathrm{MTU}$. We took no account of the fact that these assemblies had exposures different from $30000 \mathrm{MWD} / \mathrm{MTU}$ because we did not expect the measurement precision in this particular test to be sufficient to distinguish among assemblies with different exposures. The Cerenkov 
TABLE II

IMAGED ZION IRRADIATED FUEL

\begin{tabular}{|c|c|c|}
\hline $\begin{array}{l}\text { Assembly } \\
\text { Number }\end{array}$ & $\begin{array}{c}\text { Discharge } \\
\text { Date }\end{array}$ & $\begin{array}{c}\text { Exposure } \\
\text { (MWD/MTU) }\end{array}$ \\
\hline $\mathrm{A} 06 \mathrm{P}^{\mathrm{a}}$ & $03 / 76$ & 19102 \\
\hline A $18 \mathrm{~Pa}$ & $03 / 76$ & 19230 \\
\hline A $30 \mathrm{~Pa}^{a}$ & $03 / 76$ & 19224 \\
\hline A $54 \mathrm{~Pa}^{\mathrm{a}}$ & $03 / 76$ & 18821 \\
\hline $\mathrm{B} 01 \mathrm{R}^{\mathrm{a}}$ & $09 / 77$ & 30885 \\
\hline B $13 R^{\mathbf{a}}$ & $09 / 77$ & 31228 \\
\hline B $25 \mathrm{R}^{\mathrm{a}}$ & $09 / 77$ & 31009 \\
\hline B 37 R & $09 / 77$ & 27923 \\
\hline $\mathrm{B} 49 \mathrm{R}^{\mathrm{a}}$ & $09 / 77$ & 29875 \\
\hline $\mathrm{B} 61 \mathrm{R}^{\mathrm{a}}$ & $09 / 77$ & 30551 \\
\hline A $09 R$ & $02 / 78$ & 27163 \\
\hline A $21 R^{a}$ & $01 / 77$ & 20539 \\
\hline A $33 \mathrm{R}^{\mathrm{a}}$ & $01 / 77$ & 18974 \\
\hline A $45 \mathrm{R}^{\mathrm{a}}$ & $01 / 77$ & 19728 \\
\hline A $57 \mathrm{R}^{\mathrm{H}}$ & $01 / 76$ & 19723 \\
\hline $\mathrm{B} 04 \mathrm{P}$ & $02 / 78$ & 30439 \\
\hline $\mathrm{B} 16 \mathrm{P}$ & $02 / 78$ & 28969 \\
\hline $\mathrm{B} 28 \mathrm{P}$ & $02 / 78$ & 28978 \\
\hline $\mathrm{B} 40 \mathrm{P}$ & 02,78 & 30221 \\
\hline$B 52 \mathrm{l}^{2 \mathrm{a}}$ & $02 / 78$ & 30174 \\
\hline $\mathrm{B} 64 \mathrm{~Pa}^{\mathrm{Pa}}$ & $02 / 78$ & 31491 \\
\hline$(\therefore 12 \mathrm{R}$ & $09 / 78$ & 33482 \\
\hline$(124 \mathrm{R}$ & $09 / 78$ & 38484 \\
\hline ( $336 \mathrm{~K}$ & $(199 / 78$ & 33976 \\
\hline$(48 \mathrm{R}$ & $09 / 78$ & 35536 \\
\hline ( $60 \mathrm{~K}$ & $09 / 78$ & 33530 \\
\hline ( $6.3 \mathrm{P}$ & $09 / 78$ & 38565 \\
\hline ( $64 \mathrm{P}$ & $09 / 78$ & 38636 \\
\hline
\end{tabular}

photon intensities from these assemblies depend on cooling time as the calculations predicted.

An additional capability of the Cerenkov photon intensity measuring technique is the rapid profiling of the radiation intensity. At the Zion station, we requested that a single assembly, No. C $63 \mathrm{P}$, be ex-

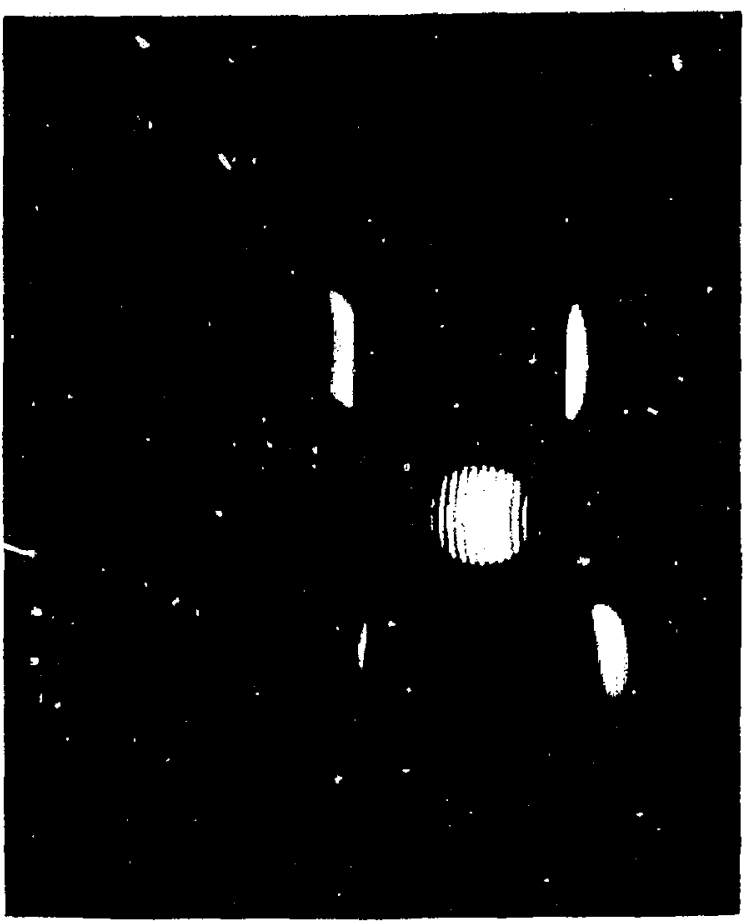

Fig. 4.

Cerenkov image of OWR elements. Individual plates of each element are discernible.

tracted from the storage rack. The SIT video camera was set up on a tripod at one end of the pond, and video images of the extracted element were recorded on video tape. A typical frame of the video image was video-disk recorded and is shown in Fig. 8. The video-disk-recorded image was displayed on the CRT with the xy cross hair raster address. With the $x$-axis cross hair disabled, the $y$-axis cross hair provides the axial Cerenkov intensity profile. This automatic trace is shown in Fig. 9. Although no detailed comparisons have been made with other measurements, this profile is typical of such PWR assemblies. $^{5}$

The vides: editor used for the Cerenkov intensity determinations and the profile display also can provide three-dimensional ( $\mathrm{x}, \mathrm{y}$, brightness) isometric displays of single video frames from a video disk. Isometric displays of OWR element arrays and 


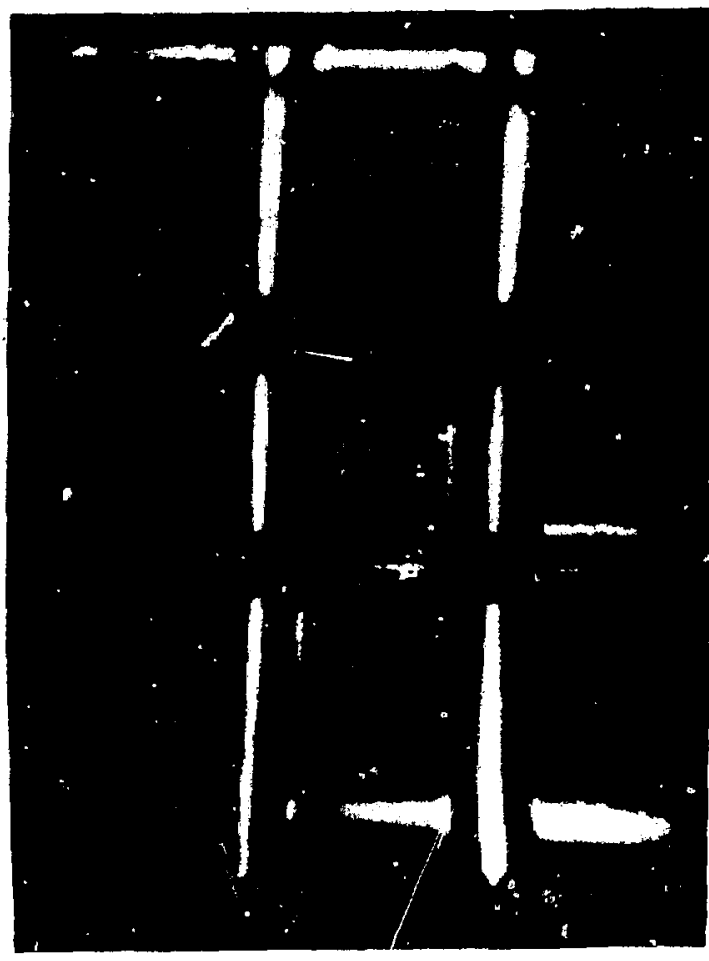

Fig. 5 .

Cerenkov image of a PWR assembly containing a burnable poison pin cluster. A typical "rosette" light pattern results.

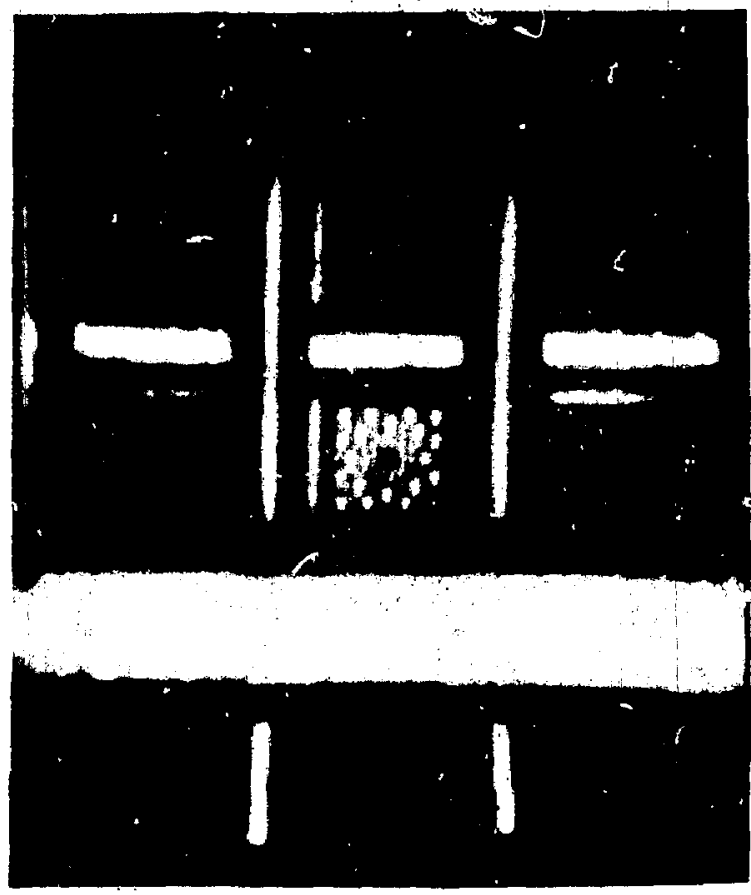

Fig. 6.

Cerenkov image of an unpoisoned PWR assembly. The bright light from the poison pin holes is clearly discernible.

TABLE III

\section{CERENKOV INTENSITIES OF OWR FUEL ELEMEN'TS}

\begin{tabular}{|c|c|c|c|}
\hline $\begin{array}{c}\text { Configuration } \\
\text { Number }^{\mathrm{B}}\end{array}$ & $\begin{array}{l}\text { Element } \\
\text { Number }\end{array}$ & $\begin{array}{c}\text { Calculated } \\
\text { Normalized } \\
\text { Intensity }\end{array}$ & $\begin{array}{c}\text { Measured } \\
\text { Normalized } \\
\text { Intensity }\end{array}$ \\
\hline I & 0.355 & 1.0 & 1.0 \\
\hline$V$ & $0-355$ & $\ldots$ & 1.1 \\
\hline VII & ()-355 & $\ldots$ & 1.9 \\
\hline $1 \mathrm{X}$ & 0.382 & 7.9 & 5.4 \\
\hline III & 0.380 & 8.6 & 7.6 \\
\hline V & $0-396$ & 18.6 & 20.6 \\
\hline
\end{tabular}

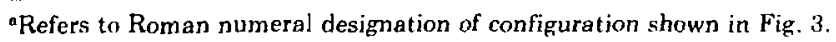




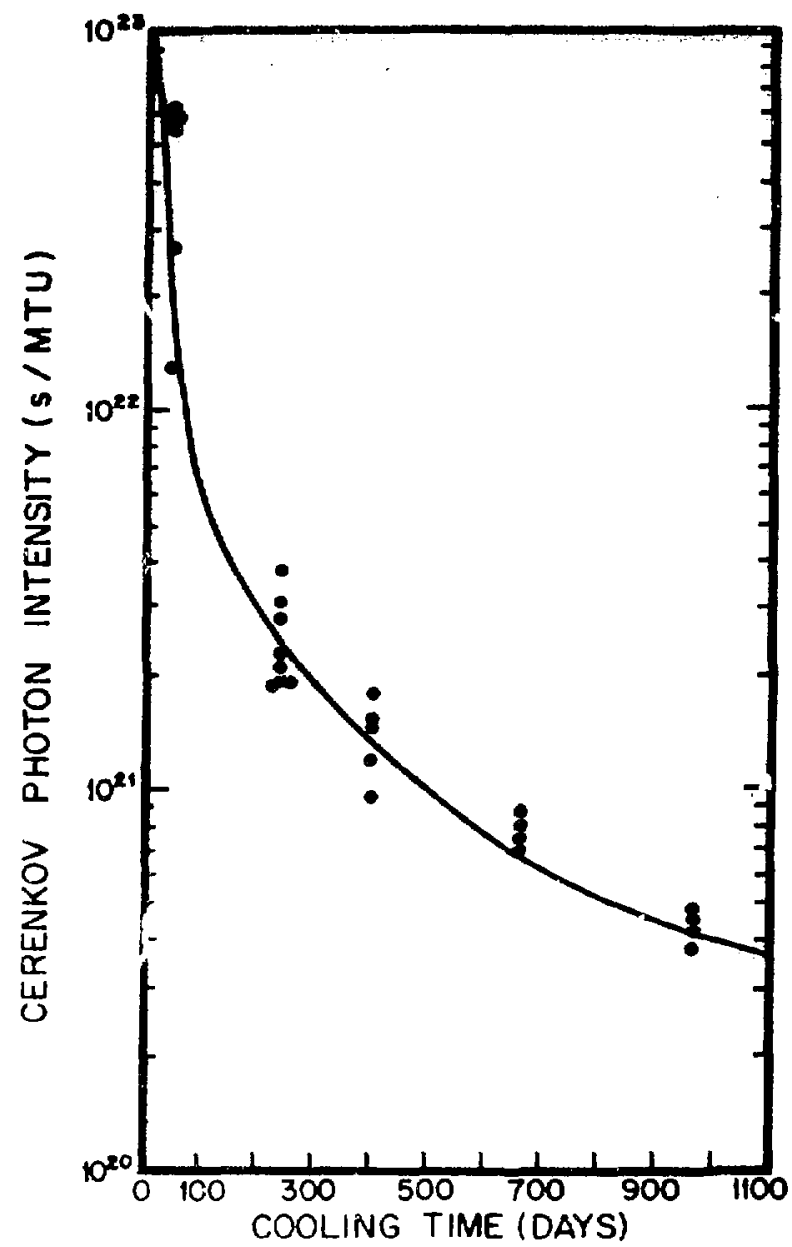

Fig. 7.

C'renkric intensity measurements of the Zion assis mblies normalized to the calculated value at 270) daw' cooling time. Solid curve is ralculated curve for $30000 \mathrm{MWD} / \mathrm{MTU}$ exposure.

PWR assembly arrays are shown in Figs. 10 and 11, respectively. This isometric feature was used to rotate the PWR assembly image shown in Fig. 8 . The result is shown in Fig. 12 with the assembly structure distinctly noted in the center porticn and the radial "halo" of the Cerenkov glow displayed as the monotonically decreasing intensity on either side of the isolated assembly. Measurement of the falloff reveals that the 10 th-value-layer thickness is

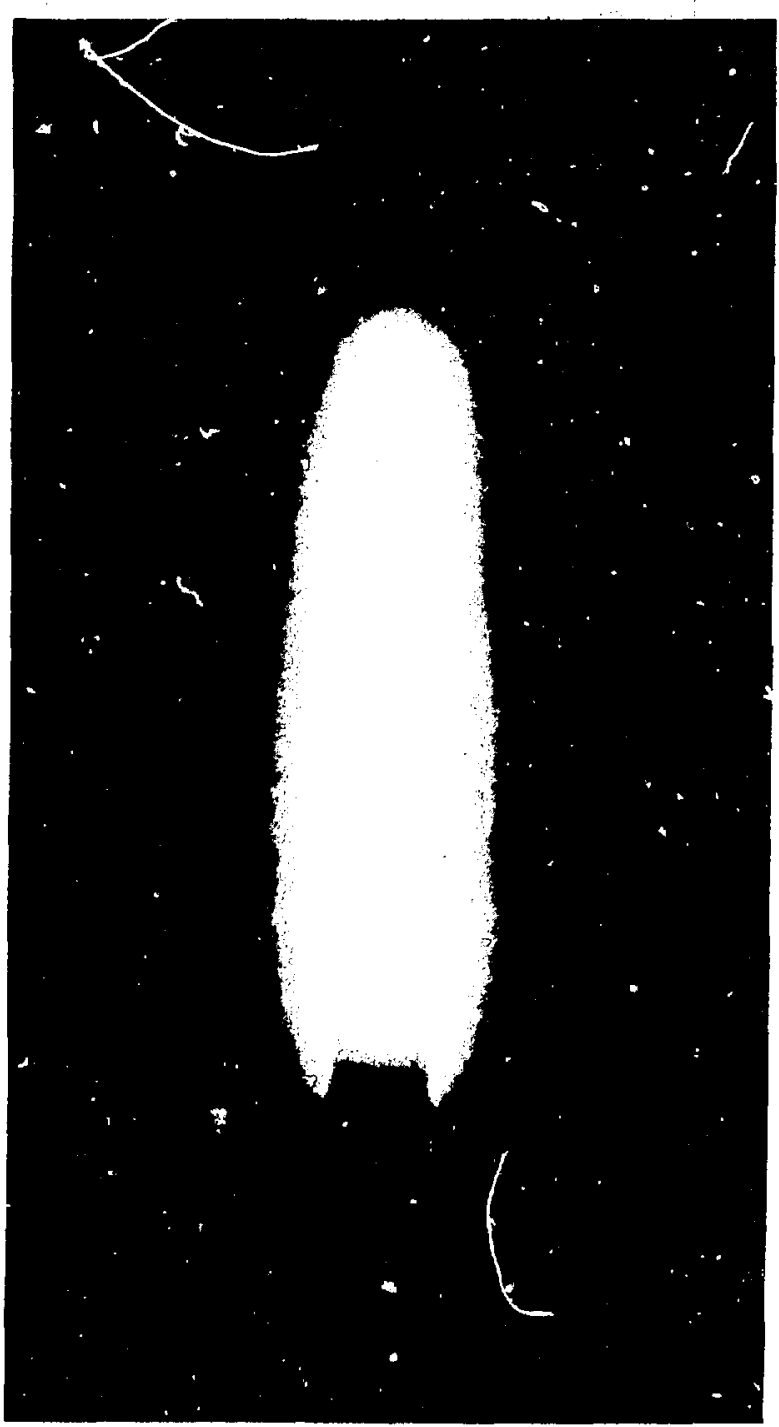

Fig. 8.

Cerenkou image of a single PWR assembly extracted from the storage rack.

about $25 \mathrm{~cm}$, somewhat less than the $36 \mathrm{~cm}$ estimated earlier for 1-MeV gamma rays. Such radial profiling may provide information about cooling time because the fission product gamma-ray spectrum changes with a known dependence on time and the Cerenkov profile is expected to change accordingly. 


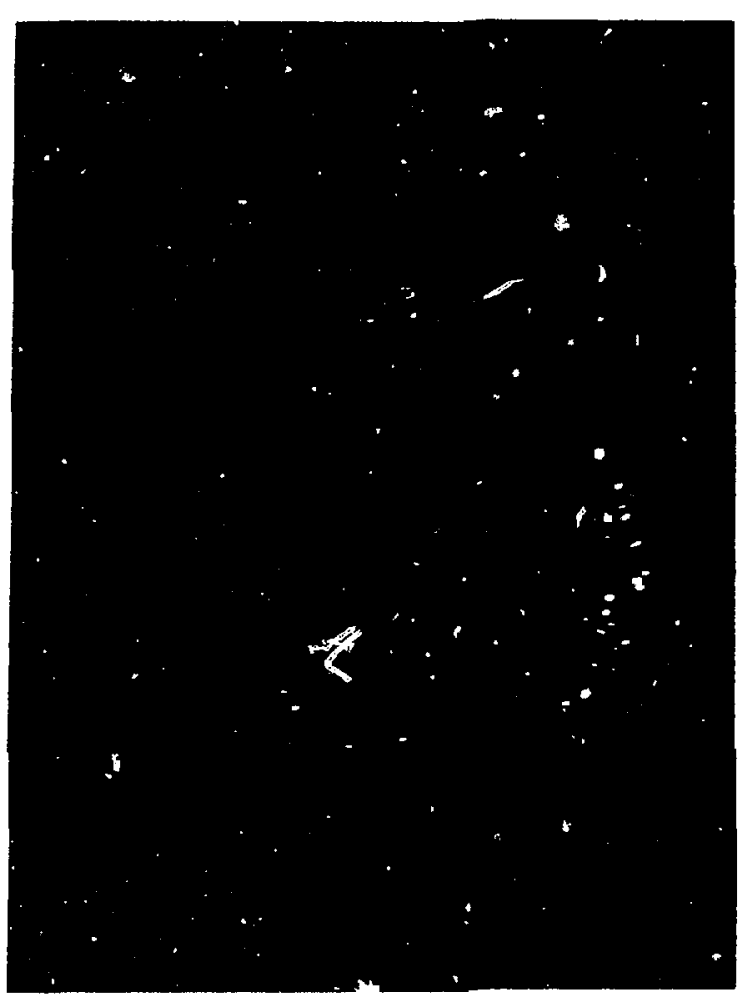

Fig. 9.

Axial profile of the Cerenkov intensity of a single PWR assembly. Obtained by analysis of a single viders frame $(1 / 30 \mathrm{~s})$.

\section{CONCLUSIONS}

We have completed a set of Cerenkov light intensity measurements from two types of spent-fuel assemblies in water-filled storage ponds. We have compared observed light ntensity as a function of burnup and cooling time with a simple computational model of the Cerenkov light production process and find reasonable agreement over a dynamic range of three decades. These intensities were measured without moving the stored assemblies from their resident locations. The precision, reproducibility, rapidity, and nonintrusiveness of these measurements make the Cerenkov light technique ideal for systematic attribute measurements on large fractions of (or entire) storage-pond inventories.

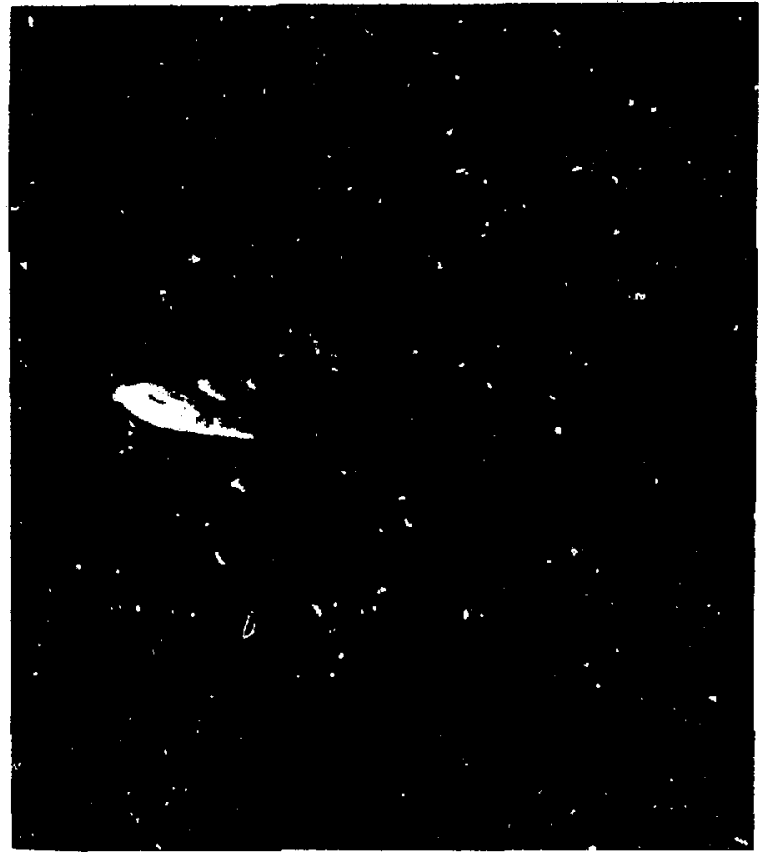

Fig. 10.

Isometric display of the Cerenkov intensity of OWR elements. Light from individual coolant channels of the element with greatest intensity are distinguishable. Light from two adjacent assemblies also visible.

The present measurements, made using an SIT video camera with off-line video tape analysis, are considered to be proof of principle of the Cerenkov light measurement technique. Thic full capability of the technique will be decermined using a highsensitivity wide dynamic-range photometer with variable field of view coupled to an ISIT video camera. Direct quantification of the Cerenkov intensity will be possible using this equipment. Comparable results are expected from fieldable instruments now under construction. This equipment will consist of telephoto optical lenses, microchannel plate image intensifiers, and $35-\mathrm{mm}$ camera backs with incorporated light meters.

We have demonstrated an additional capability of the Cerenkov light measurement technique: that of obtaining rariation profile maps of the irradiated assemblies rapidly and nonintrusively. 

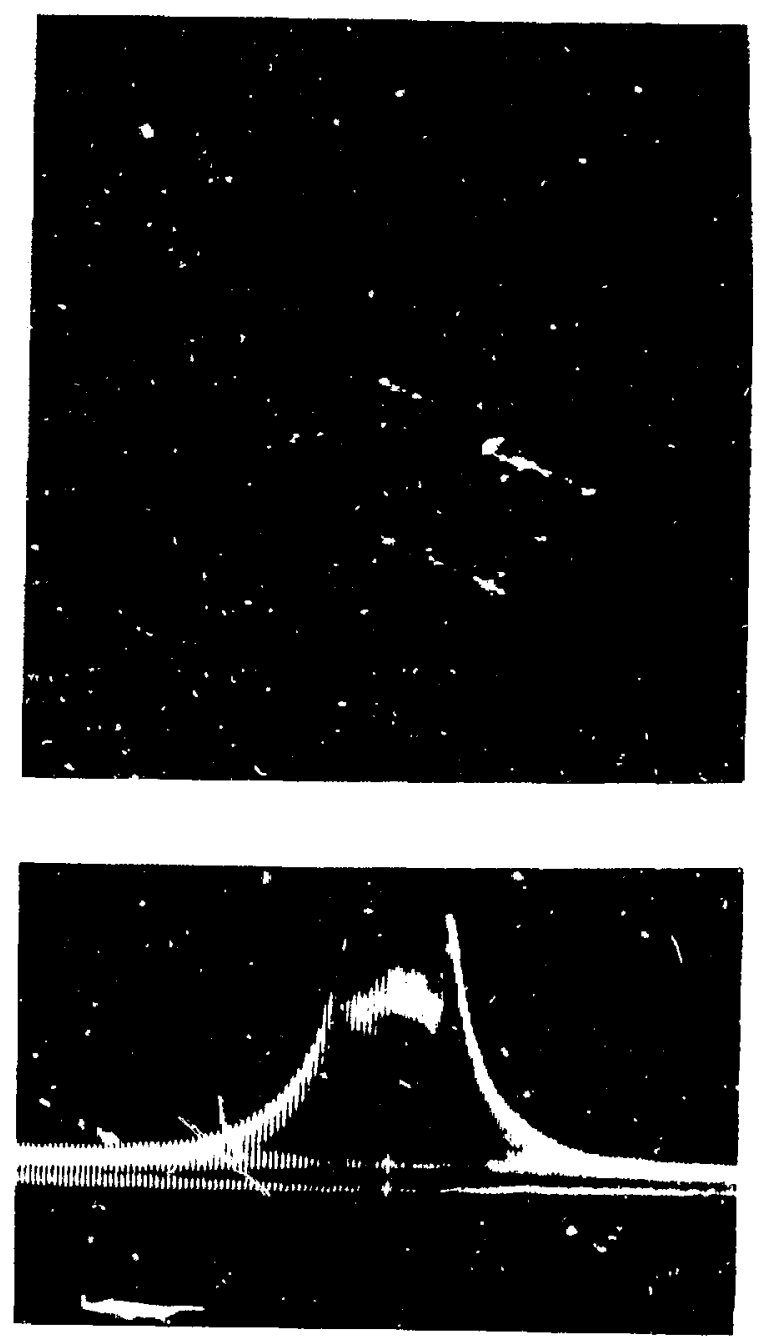

\section{REFERENCES}

1. E. J. Dowdy and J. T. Caldwell, Eds. "Irradiated Fuel Monitors: Preliminary Feasibility Study," Los Alamos Scientific Laboratory report LA-7699, ISPO No. 51 (May 1979).

2. Thomas Woodlief, Ed., SPSE Handbook of Photographic Science and Engineering (WileyInterscience, New York, 1973), p. 283.

3. E. A. Grimm, "Design and Operational Characteristics of High-Density Fuel Storage Facilities," Nucl. Tech. 43, 146 (1979).
Fig. 11 .

isometric display of the Cerenkov intensity of PWR assemblies. Light from the individual coolant holes of the aligned assembly appear as distinct spikes. Interference from adjacent assemblies appears to be negligible.

Fig. 12.

Kudial profile of the Cerenkou intensity of a single isolated PWR assembly. The less intense light in the center portion is the assembly structure.

4. E. J. Dowdy, "Interim Report on Irradiated Fuel Monitors: Cerenkov Detectors," Los Alamos Scientific Laboratory, unpublished data, 1978.

5. D. M. Lee, J. R. Phillips, S. T. Hsue, K. Kaieda, J. K. Halbig, E. G. Medina, and C. R. Hatcher, "A New Approach to the Examination of LWR Irradiated Fuel Assemblies Using Simple Gas Chamber Techniques," Los Alamos Scientific Laboratory report LA-7655-MS (March 1979). 